\title{
THE EFFECT OF PARTICLES ON TEXTURE EVOLUTION IN COMMERCIAL AIMn
}

\author{
THEO RICKERT*1, SIGRID GULDBERG**2, TROND FURU**, \\ ERIC NES**, KURT LÜCKE*
}

* Institut für Metallkunde, RWTH Aachen, W. Germany

** Inst. for Fysikalsk Metallurgi, NTH Trondheim, Norway

1 now: Allegheny Ludlum Steel, Technical Center, Brackenridge PA 15014, USA

2 now: Hydro Magnesium Materials Technology, 3900 Porsgrunn, Norway

\section{ABSTRACT}

Two commercial Aluminium alloys with high Mn content were investigated in three different precipitation states. The rolling textures possess a portion of random orientations that is proportional to the volume fraction of larger particles. It is therefore identified with their deformation zones having about double the diameter of the particles. The recrystallization textures are weak for high annealing temperatures and show the more retained rolling texture the more the temperature is lowered. This is interpreted as a matter of nucleation site. But also growth mechanisms influence the texture evolution. Minor texture components are characteristic for the different conditions.

\section{EXPERIMENTAL}

Two commercial AlMn alloys containing $1.1 \mathrm{wt.}-\% \mathrm{Mn}$ (direct cast: DC) and $2.1 \mathrm{wt.} . \%$ Mn (strip cast: SC) were investigated. Through suitable heat treatments both obtained three different precipitation states varying from highly supersaturated (DC-1, SC-1) to fully precipitated condition (DC-3, SC-3). The intermediate state (DC-2, SC-2) was achieved by $30 \%$ cold rolling of the highly supersaturated material followed by a precipitation annealing at $400^{\circ} \mathrm{C}$. The precipitation state was specified by particle size distribution and conductivity measurements. All six materials were cold rolled up to $90 \%$ and the $90 \%$ reduced specimens were recrystallized at various temperatures in a salt bath to examine rolling and recrystallization textures with the help of ODF analysis.

\section{RESULTS \& DISCUSSION}

\section{Precipitation State}

Due to the high amount of alloying elements there are coarse particles in all materials. Table 1 shows their area fractions of the larger particles and their conductivities. While 
conditions 1 and 2 have very similar size distributions and consequently about the same portion of larger precipitations, they differ strongly in their amount of dissolved foreign atoms. Therefore it can be concluded that the quantity of small particles balances the amount of supersaturated foreign atoms in condition 1, though it was not measured. However, condition 3 materials contain more and bigger particles and about no supersaturation. These major differences are much more pronounced in the SC-alloy than in DC alloy.

\section{Table 1 Pre-treatments and material conditions}

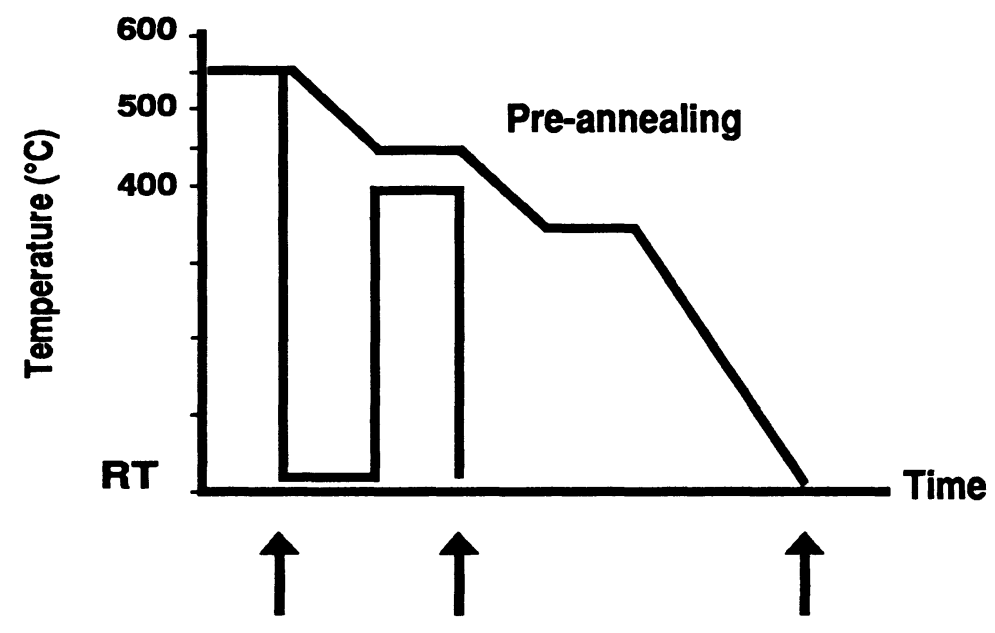

\begin{tabular}{|c|c|c|c|c|}
\hline condition & 1 & 2 & 3 & \\
\hline $\begin{array}{l}\text { DC } \\
\text { SC }\end{array}$ & $\begin{array}{l}3.2 \\
0.6\end{array}$ & $\begin{array}{l}3.4 \\
0.6\end{array}$ & $\begin{array}{l}4.1 \\
6.6\end{array}$ & $\begin{array}{c}f[\%] \\
\text { particle fraction } \\
r_{Z} 1 \mu \mathrm{m}\end{array}$ \\
\hline $\begin{array}{l}\text { DC } \\
\text { SC }\end{array}$ & $\begin{array}{l}20 \\
11\end{array}$ & $\begin{array}{l}27 \\
27\end{array}$ & $\begin{array}{l}26 \\
29\end{array}$ & 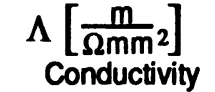 \\
\hline
\end{tabular}

\section{Rolling Textures}

During cold rolling all materials develop a Cu-type rolling texture. As can be seen favourably in B-fibre plots (fig.1), the C-component $\{112\}<111>$ is always particularly pronounced. This can be attributed to the high portion of second phase as done in other Aluminium alloys 1,2 .

Basically, the rolling textures are very similar for all materials. But they show distinctive differences in their intensities. The quantitative texture analysis relates this with the random component and discloses a strict dependency on the portion of larger particles (fig.2). 


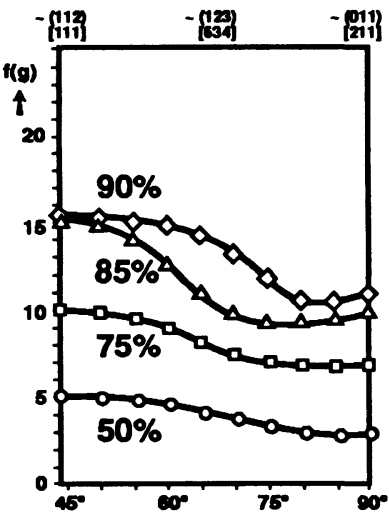

$\beta$-fibre (max. density) $\rightarrow \varphi_{2}$

a) DC-1

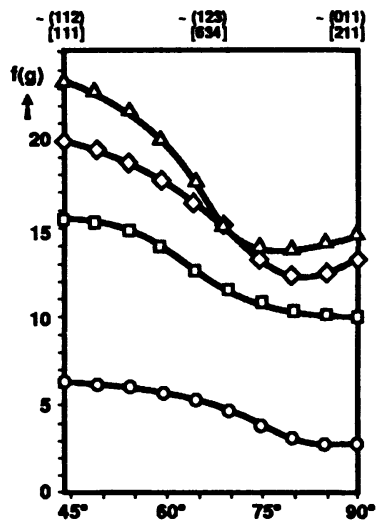

$\beta$-fibre (max. density) $\rightarrow \varphi_{2}$

d) SC-1

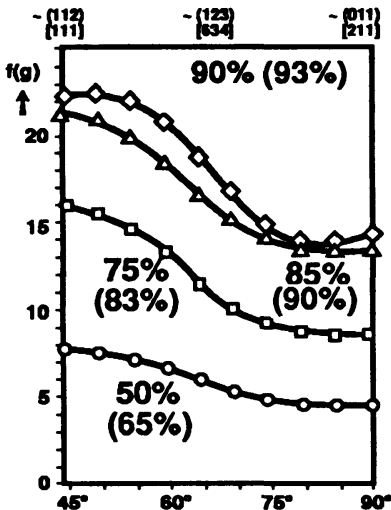

$\beta$-fibre (max. density) $\rightarrow \varphi_{2}$

b) DC-2

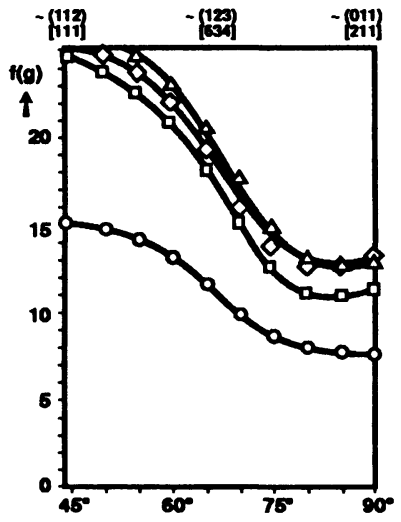

$\beta$-fibre (max. density) $\rightarrow \varphi_{2}$

e) $\mathrm{SC}-2$

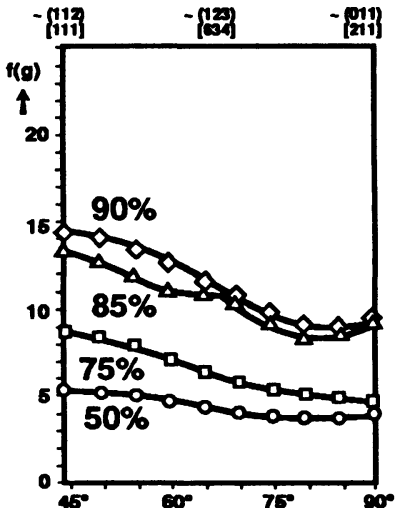

$\beta$-fibre (max. density) $\rightarrow \varphi_{2}$

c) DC-3

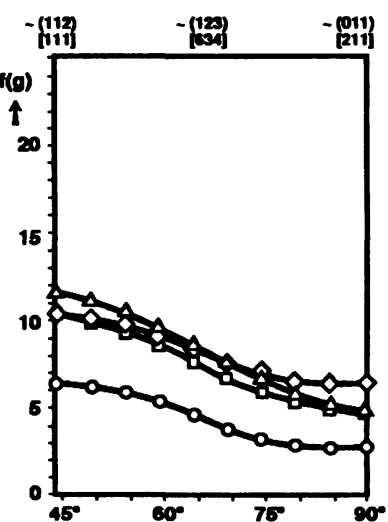

$\beta$-fibre (max. density) $\rightarrow \varphi_{2}$

f) SC-3

Figure 1. Skeleton lines of rolling textures.

In both alloys the weakest textures and highest random components are found for condition 3. As foreign atoms in supersaturation affect the texture much less than small particles, this should be compared primarily with condition 1 where the random portion is clearly lower at high reductions. Thus, the coarse particles create the random component rather than any other special texture component through the development of deformation zones $^{3}$. By attributing the random portion completely to these zones one can estimate their size to: $R \approx 2 r$ ( $R=$ zone radius, $r=$ particle radius).

Determining the random fraction of the rolling texture faces a major problem for sampling. As deformation zones are first nucleation sites, they are changing in the very first stages of recrystallization. Before any new orientation emerges in the texture, the random component decreases through recovery already at room temperature. Therefore, the detected fractions tend to be too low. 

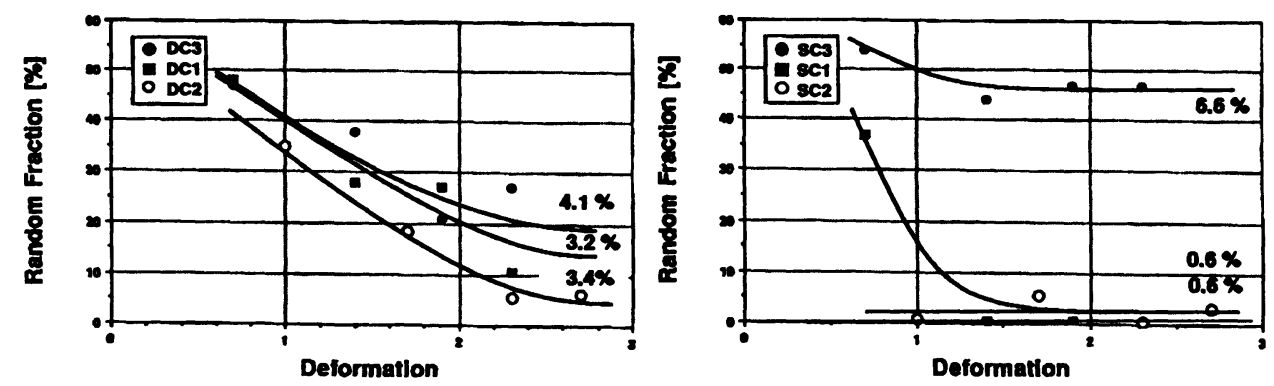

Figure 2. Volume fraction of random component during rolling.

For condition 2 showing the strongest textures, the influence of small particles and the pre-rolling also have to be considered. The $30 \%$ cold rolling prior to precipitation annealing can be included into a total deformation. Still an effect of the smaller particles on increasing the texture sharpness (as described in ${ }^{2}$ ) is found (fig.1).

The SC-materials, having a potential of nearly $7 \%$ second phase, seem to develop a sort of saturation texture which doesn't change through further rolling (fig 1d-f). This must be connected with particular microstructural processes, however, it was not further investigated.

a) $\mathrm{DC}-1,500^{\circ} \mathrm{C}$
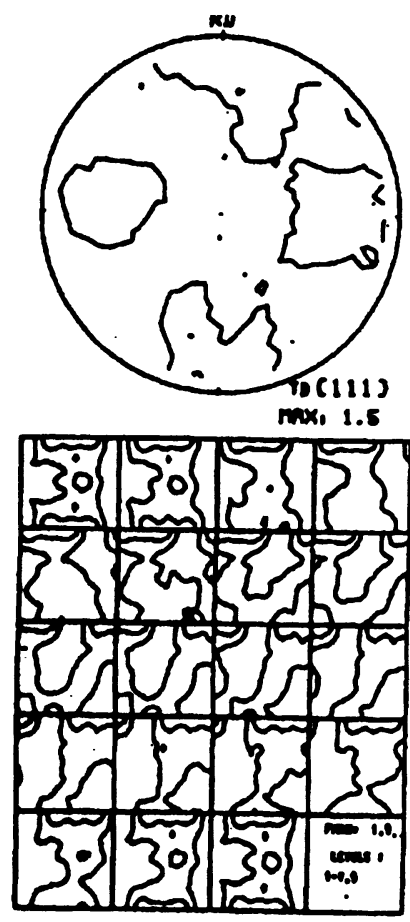

b) $\mathrm{DC}-2,500^{\circ} \mathrm{C}$

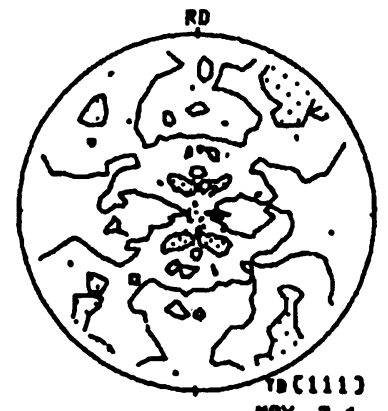

max. 2.4

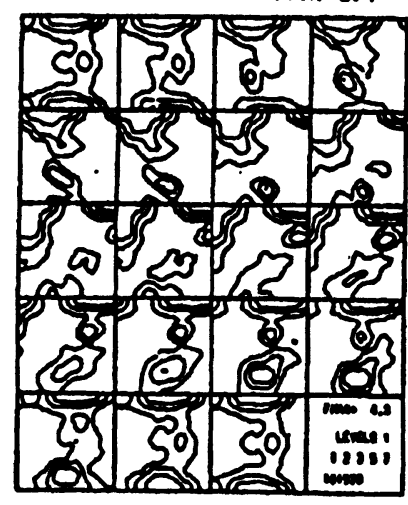

c) $\mathrm{DC}-3,500^{\circ} \mathrm{C}$

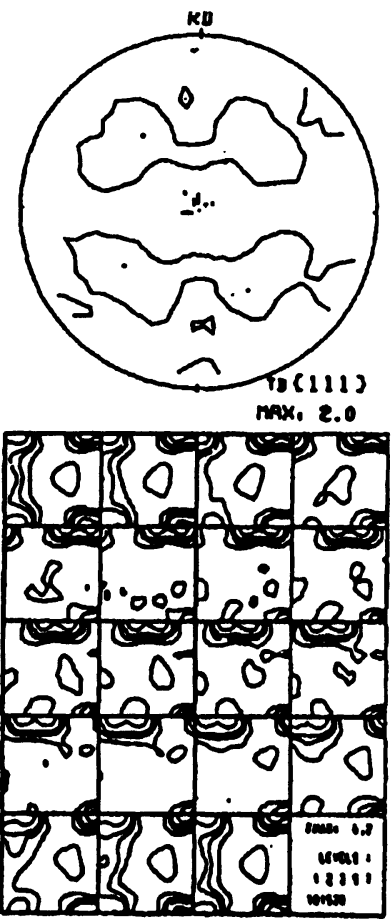

Figure 3. Recrystallization textures of DC-materials, $500^{\circ} \mathrm{C}$ 
a) $\mathrm{SC}-1,500^{\circ} \mathrm{C}$
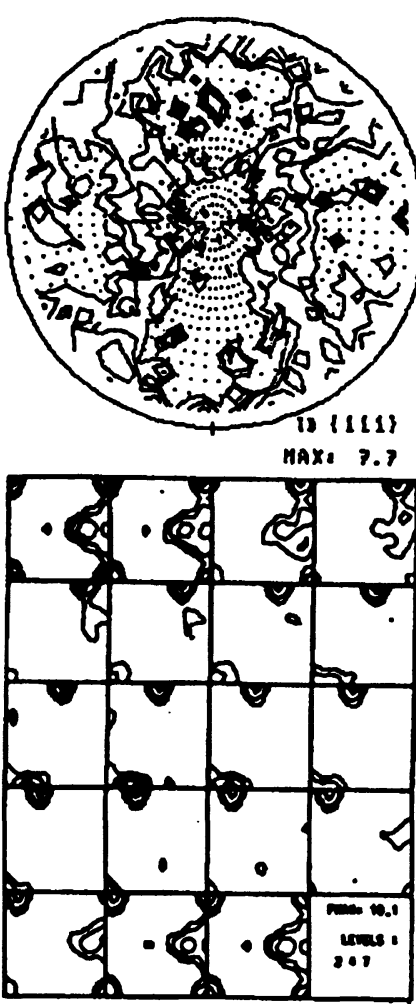

b) $\mathrm{SC} \cdot 2,500^{\circ} \mathrm{C}$

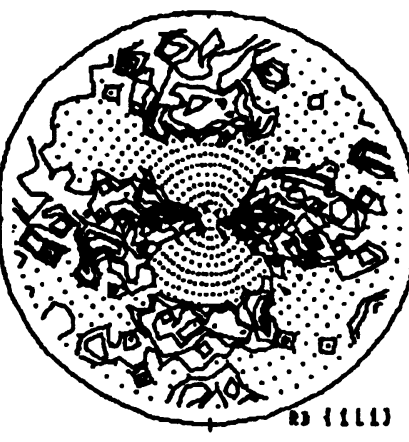

nax, 1.0

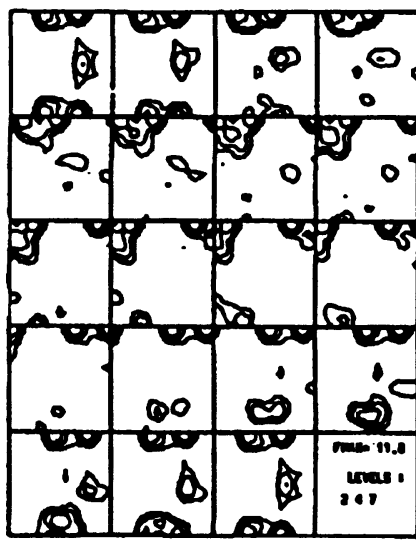

c) $\mathrm{SC}-3,500^{\circ} \mathrm{C}$

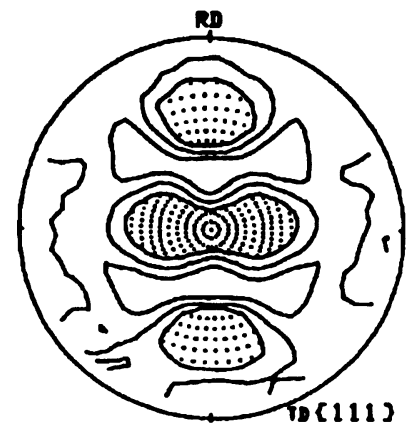

$\max 3.9$

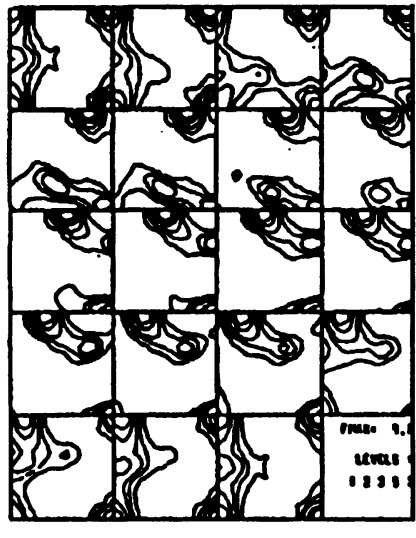

Figure 4. Recrystallization textures of SC-materials, $500^{\circ} \mathrm{C}$

\section{Recrystallization Textures}

All DC- materials form very weak recrystallization textures at high annealing temperatures (fig.3) while an increasing portion of rolling texture is retained with decreasing temperature. This harmonizes excellently with a recrystallization model of Ørsund and Nes ${ }^{4}$ who relate these texture components with different nucleation sites: (a) At high temperatures nucleation predominates in the core region of the deformation zones (random), (b) The retained rolling texture results of nucleation in the outer periphery of the zones which multiplies at lower temperatures.

Besides these two main texture components, there are minor ones (e.g.: $\{001\}<210>$ ) which are different for condition 3 than for conditions 1 and 2. But all have approximate $40^{\circ}<111>$ orientation relationships to rolling components. In fact, the texture of DC-3 after $500^{\circ} \mathrm{C}$ anneal can be seen as a nice example for the oriented growth mechanism ${ }^{5}$. It takes place as a consequence of multiple random nucleation. At lower temperatures, these components vanish and the cube component with its RD-rotations up to Goss increase, yet being minor components still. They are interpreted as being formed by a Dillamore/Katoh mechanism6. 
In conditions 1 and 2, recrystallization is strongly retarded as compared to condition 3 because of the supersaturated foreign atoms and small particles, respectively. This results in a prevention of the cube component and a change of the minor components generally. Remarkable is the evolution of the A-component $\{112\}<110>$ which is usually found only after shear deformation although there are no hints of the A-component in rolling or starting textures.

The SC-materials recrystallization is much more retarded than the DC's. SC-1 and SC2 were recrystallized only at $500^{\circ} \mathrm{C}$ forming coarse grains. But while conditions 2 and 3 develop comparable textures as the DC-materials, do SC-1 is clearly different (fig.4). The cube component is supposed to be strongly handicapped through the precipitation processes which definitely occur in the material during annealing 7 . So it's appearance here may be explained by inhomogeneities in the rolled structure in connection with a very small nucleation rate of competing orientations.

1. H.W. Erbslöh, P. Bronder and K. Lücke, Proc. ICOTOM 7, Noordwijkerhout, The Netherlands 1984, p.221

2. O. Engler, J. Hirsch and K. Lücke, Acta metall., 37, p.2743 (1989)

3. F.J. Humphreys, Acta metall., 25, p.1323 (1977)

+ F.J. Humphreys, Acta metall., 27, p.1801 (1979)

4. R. Ørsund and E. Nes, Scripta met., 22, p.671 (1988)

5. K. Lilcke, J. Hirsch, O. Engler and T. Rickert, Proc. Int. Conf. "Aluminium Alloys -

Physical and Mechanical Properties", ed. E.Starke, Charlotteville, Virginia 1986, p.1741

6. I.L Dillamore and H. Katoh, Metal Science, 8, p.73 (1974)

7. K. Ito, K. Lücke and R. Rixen, Z. Metallkunde, 67, p.338 (1976) 